\title{
ZBTB16 Overexpression Enhances White Adipogenesis and Induces Brown-Like Adipocyte Formation of Bovine White Intramuscular Preadipocytes
}

\author{
Shengjuan Wei Mengmeng Zhang Yueying Zheng Peishi Yan \\ College of Animal Science and Technology, Nanjing Agricultural University, Nanjing, China
}

\section{Key Words}

ZBTB16 - Bovine - Preadipocyte Intramuscular fat $\cdot$ Differentiation • Adipogenesis $\cdot$ Beige cell $\bullet$ Brown-like adipocyte

\begin{abstract}
Background/Aims: Our study aims to characterize functions of ZBTB16 gene in the process of intramuscular fat (IMF) deposition and metabolism of bovine, thereby providing insights into mechanisms for the use of ZBTB16 in fat management. Methods: Primary preadipocytes derived from bovine IMF tissue were isolated and used as the in vitro cell model. An adenovirus Ad-ZBTB16 was transfected into bovine preadipocytes to overexpress the ZBTB16 gene. By using real-time quantitative PCR (RT-qPCR), western blotting, Oil Red-O staining, glycerol-3-phosphate dehydrogenase (GPDH) activity assay, and cell counting kit-8 (CCK-8) test, adipogenic and proliferative signals in adipocytes were monitored to investigate effects of ZBTB16 on adipogenesis of bovine preadipocytes. Results: After transfection, mRNA and protein levels of ZBTB16 gene were significantly increased. Enhanced ZBTB16 significantly promoted preadipocyte differentiation, as evidenced by accelerated lipid accumulation, enhanced GPDH activity, consistently increased mRNA expressions of adipogenic key transcription factors PPAR $\gamma, C / E B P \alpha, F A B P 4$, and ADIPOQ and markedly increased protein expressions of PPARY and FABP4. No difference was observed concerning proliferation of preadipocytes after treatment with Ad-ZBTB16. Furthermore, relative mRNA levels of brown adipocyte selective genes (PRDM16, UCP1, Cidea, Cox8b, and PGC-1 $\alpha$ ) and beige adipocyte selective genes (CD137, TMEM26, and Tbx1) as well as UCP1 protein expression were significantly increased by Ad-ZBTB16. Meanwhile, Ad-ZBTB16 treatment remarkably induced mitochondrial biogenesis and increased relative mitochondrial DNA (mtDNA) copy number in bovine adipocytes. Conclusion: These results suggest that ZBTB16 overexpression can promote white adipogenesis and induce brown-like adipocyte formation for bovine white intramuscular preadipocytes.

(C) 2018 The Author(s)
\end{abstract}




\section{Introduction}

Adipose tissue is composed primarily of a large number of adipocytes, which are generated through the proliferation (number increase) and differentiation (size increase) of preadipocytes [1]. Dysfunction of adipocyte and adipose tissue may cause health problems such as human obesity and metabolic syndrome [2,3]. Additionally, adipose tissue deposition is highly related to meat quality and animal productivity in farm animals $[4,5]$. Therefore, understanding mechanisms regulating adipose tissue development would be highly beneficial to both human health and animal production.

Adipose tissue between muscle fibers is usually referred to as intramuscular fat (IMF) [6]. In cattle, IMF accumulation makes beef appear marbling and contributes to beef flavor and juiciness [7]. In order to improve beef quality, it is vital to find factors that regulate preadipocyte proliferation and differentiation because the mass of adipose tissue is controlled by the process of adipogenesis. It has been reported that the differentiation of preadipocytes into adipocytes is controlled by a complex network of transcription factors, such as peroxisome proliferator-activated receptor gamma (PPAR $\gamma$ ) and CCAAT/enhancer binding protein alpha $(\mathrm{C} / \mathrm{EBP} \alpha)$, the master regulators driving adipogenesis, as well as fatty acid binding protein 4 (FABP4) and adiponectin (ADIPOQ), the important adipogenic markers regulating adipogenesis [8].

Zinc finger and BTB domain containing 16 (ZBTB16), also known as PLZF and Zfp145, belongs to the Krüppel-like zinc finger protein family [9]. Previous studies have demonstrated that ZBTB16 is an important transcriptional repressor or activator [10], involved in various developmental and biological processes such as myeloid development [11], spermatogenesis $[12,13]$, hind limb formation [14], cellular apoptosis [15], and anti-tumorigenesis [16], etc. ZBTB16 also plays a role in the regulation of hematopoietic stem cell fate and homeostasis [17]. In addition, comparative epigenomic and transcriptome studies suggest ZBTB16 gene to be a new candidate modulator of adipogenesis regulating fat development $[18,19]$. In brown fat and muscle, ZBTB16 has been uncovered regulating thermogenic program [20]. Our purpose is focused on the role of ZBTB16 in intramuscular preadipocyte proliferation and differentiation because intramuscular fat is the basic material for the formation of marbling in livestock and identifying key genes regulating IMF adipogenesis for improvement of meat quality is feasible in molecular genetics. Furthermore, as beige adipocytes dissipate energy as heat and are not preferable in beef cattle, determining genes that induce fat browning is also important. Thus, effects of ZBTB16 on browning of IMF preadipocytes are also detected.

\section{Materials and Methods}

\section{Experimental animals and reagents}

Samples of longissimus dorsi muscle from Simental steers were collected at a local slaughterhouse (Nanjing, Jiangsu, China). The Experimental Animal Care and Use Committee of Nanjing Agricultural University approved the use of animals and procedures in this research.

DMEM/F12 medium used in this study was obtained from Hyclone (Logan, UT) and supplemented with $100 \mathrm{IU} / \mathrm{mL}$ penicillin and $100 \mu \mathrm{g} / \mathrm{mL}$ streptomycin. Fetal bovine serum (FBS) was from Sciencell (San Diego, CA). To achieve a high efficient transfection in primary cultured adipocytes, an adenovirus Ad-ZBTB16 (Hanbio Biotechnology Co., Ltd., Shanghai, China) carrying bovine ZBTB16 and GFP (green fluorescent protein) genes was employed. Cells treated with Ad-GFP (Hanbio, Shanghai, China) were used as a negative control and non-treated cells were used as a blank control. Multiplicity of infection (MOI) of 250 with a 4-h transfection time was performed in this study. The efficiency of transfection was observed at $24 \mathrm{~h}$ post-transfection using an inverted fluorescence microscope (CKX41, Olympus, Japan). 


\section{Cellular Physiology Cell Physiol Biochem 2018;48:2528-2538 \begin{tabular}{ll|l} 
and Biochemistry Published onlıne: 16 August, 2018 & $\begin{array}{l}\text { (c) } 2018 \text { The Author(s). Published by S. Karger AG, Basel } \\
\text { www.karger.com/cpb }\end{array}$ \\
\hline
\end{tabular}

\section{IMF-derived adipocyte isolation and culture}

The isolation and culture of bovine IMF-derived adipocytes were performed as previously described with minor alterations [21]. Briefly, intramuscular fat tissue was isolated from the muscle samples under sterile conditions and then cut into approximately $1 \mathrm{~mm}^{3}$ sections. The tissue was digested with type I collagenase at $37^{\circ} \mathrm{C}$ for $60 \mathrm{~min}$ in a shaking water bath, followed by filtration through a $100 \mu \mathrm{m}$ and then a $40 \mu \mathrm{m}$ cell strainer. The filtrate was centrifuged at 1, $200 \mathrm{rpm}$ for $10 \mathrm{~min}$. After centrifugation, the supernatant containing mature adipocytes was collected for RNA and protein extraction. The pellet containing preadipocytes was re-suspended in DMEM/F12 $+10 \%$ FBS media and incubated at $37^{\circ} \mathrm{C}$ in a humidified atmosphere containing $5 \% \mathrm{CO}_{2}$. All media were changed every 2 or 3 days.

\section{Cell proliferation test}

Bovine preadipocytes were seeded in 96-well culture plates and incubated with Ad-ZBTB16. At 24h post-transfection, the effect of ZBTB16 overexpression on cell proliferation was assessed using a cell counting kit-8 (CCK-8; Vazyme, Nanjing, China) according to the manufacturer's protocol, followed by absorbance measurement at $450 \mathrm{~nm}$ by a microplate reader (Thermo).

\section{Adipogenic differentiation}

Two days after confluence (d 0), differentiation of preadipocytes was induced by a standard DMI (inductive differentiation medium) cocktail, containing $1 \mu \mathrm{g} / \mathrm{mL}$ insulin, $1 \mu \mathrm{M}$ dexamethasone, $0.5 \mathrm{mM}$ isobutylmethylxanthine, and $2 \mu \mathrm{M}$ rosiglitazone, for 6 days and then maintained in insulin $(1 \mu \mathrm{g} / \mathrm{mL})$ supplemented medium for 2 days. To investigate ZBTB16 overexpression effect on adipogenic differentiation, preadipocytes were transfected with Ad-ZBTB16 at d 0 of differentiation. RNA and protein were extracted by TRIzol (Ambion, Austin, TX) reagent at various time points during differentiation. At d 8 of differentiation, adipocytes were stained with Oil Red-0 and observed under an inverted fluorescence microscope. Lipid contents were quantified based on the absorbance values at $510 \mathrm{~nm}$ of destained Oil Red-0 extracted from the cells by a microplate reader [22]. Additionally, at d 8 of differentiation, MitoTracker Red (Invitrogen, Carlsbad, CA) and DAPI (4', 6-diamidino-2-phenylindole; Invitrogen) were used to stain mitochondria and nuclei, respectively. Images of the cells were captured under a confocal laser scanning microscope (LSM 700, Carl Zeiss, Oberkochen, Germany).

\section{Glycerol-3-phosphate dehydrogenase (GPDH) activity assay}

The GPDH activity was measured using the GPDH activity assay kit (Takara, Shiga, Japan). Briefly, differentiated adipocytes were rinsed with PBS, scraped into enzyme extraction buffer and sonicated. After centrifugation at $10,000 \mathrm{rpm}$ for $5 \mathrm{~min}$, the GPDH activity in supernatants was determined spectrophotometrically at $340 \mathrm{~nm}$ with the GPDH assay kit. Protein concentration was measured using a BCA (bicinchoninic acid) protein assay kit (Cell Signaling, Boston, MA) to correct the GPDH assay results.

\section{Real-time quantitative PCR (RT-qPCR)}

The RT-qPCR was performed using the StepOne Real-time PCR system (Applied Biosystems, Foster, CA) and the SYBR Premix Ex Taq ${ }^{\text {TM }}$ (Takara, Dalian, China). Primers were designed and synthesized by Shanghai Sangon Biological Engineering Technology Services Co., Ltd (Shanghai, China). Primer information is shown in Table 1. Glyceraldehyde-3-phosphate dehydrogenase (GAPDH) was used as the reference gene. The data were processed using the $2^{-\Delta \Delta \mathrm{CT}}$ method.

Measurement of mitochondrial DNA (mtDNA) Copy Number

Relative mtDNA copy number was measured by RT-qPCR as previously described [23]. In brief, genomic DNA was extracted from cells with phenol/chloroform. The levels of mtDNA were measured by amplification of $\mathrm{NADH}$ dehydrogenase subunit 1 (ND1) gene (forward: 5 ' - CGTAGAATAT G CAGCAGGACCA-3';
Table 1. Primer sequences for RT-qPCR

\begin{tabular}{llllc}
\hline Gene & GenBank ID & Forward primer sequence (5' to 3') & Reverse primer sequence (5' to 3') & Product size \\
\hline ZBTB16 & NM_001037476.2 & GCATGATCCAGCTGCAGAAC & AACTCCTGGCTGTCCACCAT & $115 \mathrm{bp}$ \\
PPARY & NM_181024.2 & TGGAGACCGCCCAGGTTTGC & AGCTGGGAGGACTCGGGGTG & $111 \mathrm{bp}$ \\
C/EBP $\alpha$ & NM_176784.2 & TGGGCAAGAGCCGGGACAAG & ACCAGGGAGCTCTCGGGCAG & $166 \mathrm{bp}$ \\
FABP4 & NM_174314.2 & TCCTTCAAATTGGGCCAGGAA & CCCTTGGCTTATGCTCTCTCA & $218 \mathrm{bp}$ \\
ADIPOQ & NM_174742.2 & TCCTACTTCCACCCTGACTG & GGGGGATCTTCCATGTTGTCC & $132 \mathrm{bp}$ \\
PRDM16 & FI796200.1 & CGACTTCGAGGACATCAACA & CCTTGTCCTTGGTCTTGTCG & $113 \mathrm{bp}$ \\
UCP1 & NM_001166528 & AACCCACAGAGGTGGTCAAG & CCGTCAAGCCTTCTGTTGTT & $120 \mathrm{bp}$ \\
Cidea & NM_001083449.1 & CCTACGACATCCACTGCACA & AGCACTCGGAGCATGTAGGT & $124 \mathrm{bp}$ \\
Cox8b & NM_001114517.2 & CCTAAGGCACACATCACTGC & AGGAAGCTGAGGAACGTCAC & $92 \mathrm{bp}$ \\
PGC-1 $\alpha$ & NM_177945.3 & GATGTGACCACGGAGAATGA & TAGCTGAGTGTTGGCTGGTG & $123 \mathrm{bp}$ \\
CD137 & NM_001035336.2 & GCAGGATGTTCCATGTGTGA & GACAGATGCCATGTTCCTGA & $112 \mathrm{bp}$ \\
TMEM26 & NM_001103163.2 & TTGTTGTGCGGCTCATACTC & GTACATCCAAGGCCACACC & $129 \mathrm{bp}$ \\
Tbx1 & XM_019977115.1 & TGGCTGACTACATGCTCCTC & TGTCGAAGGAGACAATCTGC & $186 \mathrm{bp}$ \\
GAPDH & NM_001034034.2 & TGCCGGTTCGACAGATAGCC & GCGACGATGTCCACTTTGCC & $148 \mathrm{bp}$ \\
\hline & & & &
\end{tabular}




\section{Cellular Physiology Cell Physiol Biochem 2018;48:2528-2538 \begin{tabular}{l|l|l} 
and Biochemistry Published online: 16 August, 2018 & $\begin{array}{l}\text { @ } 2018 \text { The Author(s). Published by S. Karger AG, Basel } \\
\text { www.karger.com/cpb }\end{array}$ \\
\hline
\end{tabular}

reverse: 5'-GTTCTGGTATGTGTGGATTGTGG-3'), and nuclear-encoded GAPDH gene was amplified simultaneously for normalization. The relative mtDNA copy number was determined by the ratio of mtDNA to nuclear DNA and calculated by the $2^{-\Delta C T}$ method $\left(\Delta \mathrm{CT}=\mathrm{CT}_{\mathrm{ND1}}-\mathrm{CT}_{\mathrm{GAPDH}}\right)$.

\section{Western blotting analysis}

The concentration of protein was quantified using a BCA protein assay kit. Equal amounts $(30 \mu \mathrm{g})$ of proteins were separated by SDS-PAGE and transferred to polyvinylidene fluoride membranes. After blocking in defatted 5\% milk, the membranes were immunoblotted with rabbit anti-ZBTB16 (Abcam, Cambridge, MA), PPAR $\gamma$ (Santa Cruz, Santa Cruz, CA), FABP4 (LifeSpan Biosciences, Seattle, WA), UCP-1 (BIOSS, Beijing, China), or $\beta$-actin (Cell Signaling Technology, Danvers, MA) antibody overnight at $4{ }^{\circ} \mathrm{C}$, followed by incubation with anti-rabbit IgG secondary antibody for $1 \mathrm{~h}$ at room temperature. Then protein bands were visualized using an enhanced chemiluminescence detection system (Amersham, Piscataway, NJ). Protein band density was quantified and normalized to the $\beta$-actin content.

\section{Statistical analysis}

All data were obtained from at least three independent experiments. Results were expressed as mean \pm SEM. Statistics were calculated with SPSS software (version 20.0). One-way ANOVA was used for comparisons among groups, followed by Duncan test. The two-tailed t test was used to analyze ZBTB16 expression differences between preadipocytes and mature adipocytes. Differences with $\mathrm{P}$ values less than 0.05 and 0.01 were deemed statistically significant and very significant, respectively.

\section{Results}

\section{ZBTB16 is up-regulated during differentiation of bovine IMF-derived preadipocytes}

Preadipocytes and mature adipocytes directly isolated from bovine IMF tissue were collected to compare the ZBTB16 gene expressions. As shown in Fig. 1A, mature adipocytes had very significantly higher expressions of ZBTB16 in mRNA level compared with preadipocytes $(\mathrm{P}<0.01)$. Moreover, through differentiation of bovine IMF-derived preadipocytes, mRNA expressions of ZBTB16 were consistently up-regulated at indicated time points ( $\mathrm{P}<0.01 ;$ Fig. 1B). In accordance with mRNA level, protein expression of ZBTB16 in mature adipocytes was markedly higher than that in preadipocytes (Fig. 1C), and ZBTB16 protein was progressively increased from day 0 to day 8 of differentiation (Fig. 1D).

\section{Detection of overexpression effect of Ad-ZBTB16 in preadipocytes}

The Ad-ZBTB16 (containing bovine ZBTB16 gene and GFP gene) was transfected into bovine preadipocytes to detect transfection and overexpression effect of Ad-ZBTB16 on the cells. The un-transfected cells and the Ad-GFP (containing GFP gene) transfected cells

Fig. 1. Expressions of ZBTB16 gene in bovine IMF-derived adipocytes. (A) ZBTB16 mRNA levels in preadipocytes and mature adipocytes. (B) The timespatial mRNA expressions of ZBTB16 during differentiation of preadipocytes. Data were compared with day 0 . (C) ZBTB16 protein expression levels in preadipocytes and mature adipocytes. (D) ZBTB16 protein expression levels during differentiation of preadipocytes. $* *$

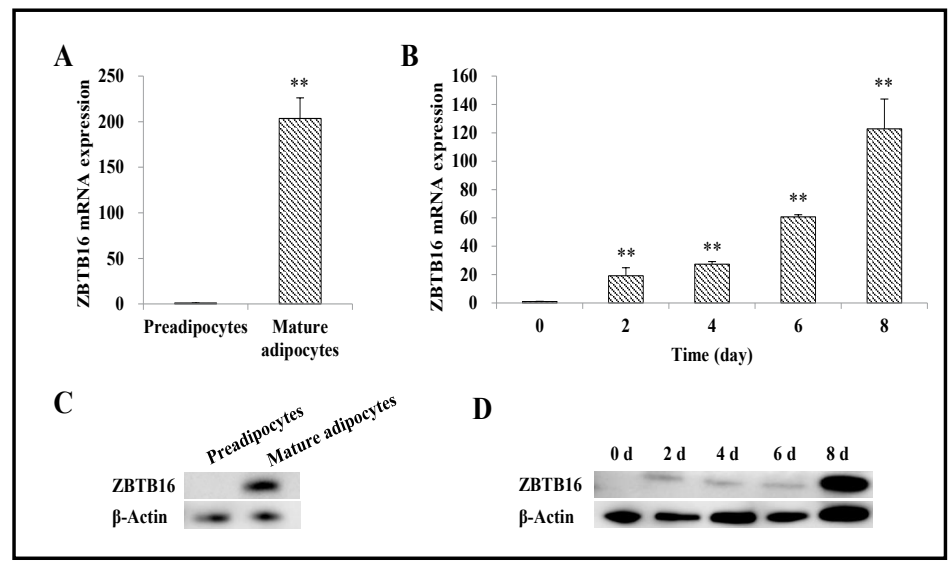
$\mathrm{P}<0.01$. 


\section{Cellular Physiology

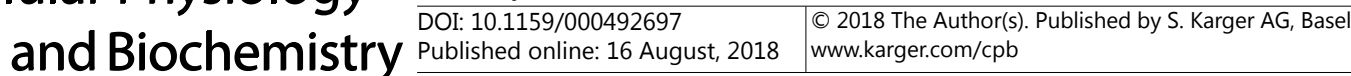 \\ Wei et al.: ZBTB16 Induces Beige Cell Formation}

Fig. 2. Detection of overexpression effect of Ad-ZBTB16 in bovine IMF-derived preadipocytes. (A) Fluorescence micrographs of bovine preadipocytes at $24 \mathrm{~h}$ posttransfection (100 × magnification). (B) ZBTB16 mRNA levels in bovine preadipocytes at $24 \mathrm{~h}, 48 \mathrm{~h}$ and $72 \mathrm{~h}$ post-transfection in different treatment groups. (C) ZBTB16 protein expression levels in bovine adipocytes after transfection with Ad-ZBTB16 for 48 h. ${ }^{* *} \mathrm{P}<0.01$.

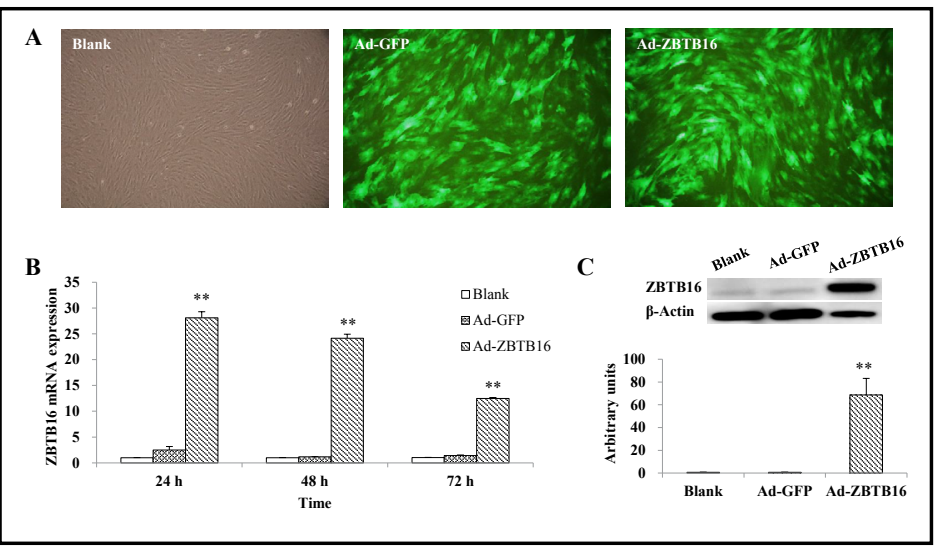

were used as the blank control and AdGFP negative control, respectively. After $24 \mathrm{~h}$, successful transfection was observed as the expression of GFP by fluorescence microscopy (Fig. 2A), whereas the untransfected blank control group did not show fluorescence.

As expected, the relative levels of ZBTB16 mRNA at $24 \mathrm{~h}, 48 \mathrm{~h}$ and $72 \mathrm{~h}$ post-transfection were very significantly higher than those in blank control and AdGFP control groups ( $<<0.01$; Fig. 2B). No significant difference was found between the two control groups $(\mathrm{P}>0.05)$. Consistent

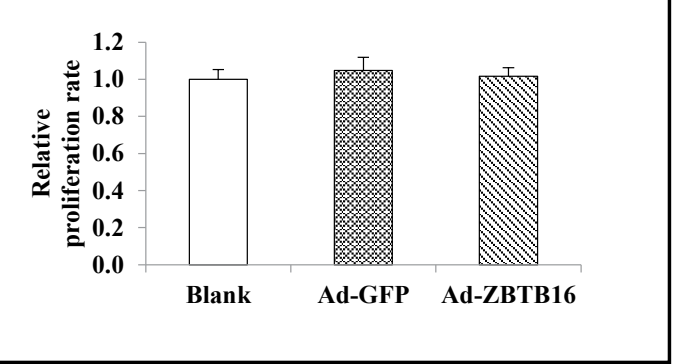

Fig. 3. Effect of Ad-ZBTB16 on proliferation of bovine IMF-derived preadipocytes. Preadipocytes were transfected with Ad-ZBTB16 and cell proliferation was assessed at $24 \mathrm{~h}$ post-transfection. with mRNA levels, protein expression level of ZBTB16 in Ad-ZBTB16 treated cells was very significantly higher at $48 \mathrm{~h}$ post-transfection ( $\mathrm{P}<0.01$; Fig. $2 \mathrm{C}$ ), compared with the blank and the Ad-GFP control groups. Protein level of ZBTB16 in the blank and the Ad-GFP control groups did not show significant differences $(P>0.05)$. These results suggest that the use of the Ad-ZBTB16 is feasible and suitable for further study.

\section{Ad-ZBTB16 does not change proliferation of bovine IMF-derived preadipocytes}

Bovine IMF-derived preadipocytes were transfected with Ad-ZBTB16 and cell proliferation was assessed after the cells were transfected for $24 \mathrm{~h}$. The un-transfected cells and the Ad-GFP transfected cells were used as the control. No significant difference was observed among the Ad-ZBTB16 group, the Ad-GFP group, and the un-transfected blank group (P > 0.05; Fig. 3).

\section{Ad-ZBTB16 enhances adipogenesis of bovine IMF-derived preadipocytes}

To determine whether Ad-ZBTB16 has a direct effect on bovine white adipocyte differentiation, the Ad-ZBTB16 was transfected into preadipocytes, taking un-transfected cells and Ad-GFP transfected cells as the reference effects, and then stimulated to differentiate for eight days. At day 8, formation of lipid droplets was observed by staining with Oil Red-O (Fig. 4A). The Ad-ZBTB16 obviously increased the number of lipid droplets in bovine adipocytes relative to control groups. The amount of lipid content was quantified based on absorbance values, which showed Ad-ZBTB16 could significantly increase lipid accumulation in adipocytes ( $<<0.01$; Fig. 4B). Meanwhile, Ad-ZBTB16 markedly upregulated GPDH activity compared with that in control cells ( $\mathrm{P}<0.01 ;$ Fig. $4 \mathrm{C})$. No significant difference about lipid content and GPDH activity was found between the blank control and the Ad-GFP control groups $(\mathrm{P}>0.05)$. 
Fig. 4. Effect of Ad-ZBTB16 on differentiation of bovine IMF-derived preadipocytes. Preadipocytes were induced to differentiate and treated with AdZBTB16 at d 0 of differentiation for 8 days. (A) Lipid accumulation was monitored with Oil Red-0 staining under a microscope (100 $\times$ magnification). (B) Quantification of lipid content by measuring the absorbance at $510 \mathrm{~nm}$. (C) Analysis of GPDH activity. ${ }^{* *} \mathrm{P}<0.01$.

Fig. 5. Effect of Ad-ZBTB16 on relative expressions of key adipogenic genes in bovine IMF-derived preadipocytes. Preadipocytes were induced to differentiate and treated with AdZBTB16 at d 0 of differentiation. The cells were harvested for RTqPCR analysis at $24 \mathrm{~h}(\mathrm{~A}), 48 \mathrm{~h}(\mathrm{~B})$, and $d 8(C)$, respectively, followed by western blotting test at $\mathrm{d} 8$ (D). ** $\mathrm{P}<0.01$.
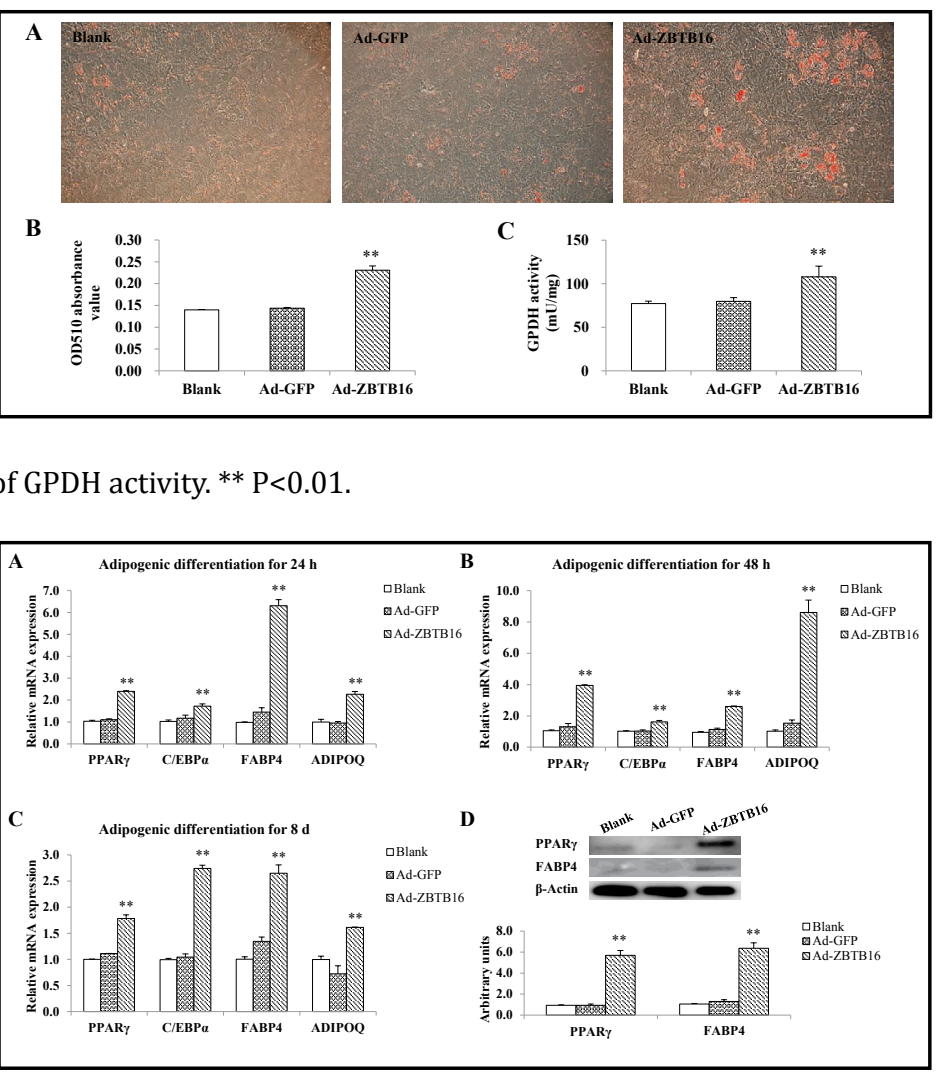

Fig. 6. Effect of Ad-ZBTB16 on brown-like adipocyte formation of bovine IMF-derived preadipocytes. Preadipocytes were treated with Ad-ZBTB16 and induced to differentiate atd 0 of differentiation. At d 8 of differentiation, cells were subjected to the following detections. (A) Relative mRNA levels of brown adipocyte selective genes (PRDM16, UCP1, Cidea, Cox8b, and PGC- $1 \alpha$ ) and beige adipocyte selective genes (CD137, TMEM26, and Tbx1). (B) Western bolt analysis of UCP1 gene. (C)

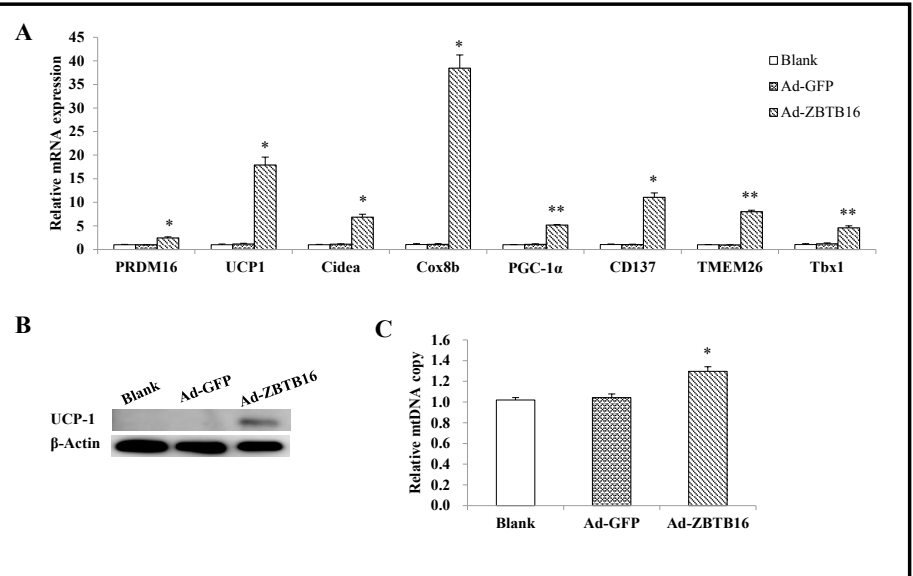

Relative mitochondrial DNA (mtDNA) copy number. ${ }^{*} \mathrm{P}<0.05$; ${ }^{* *} \mathrm{P}<0.01$.

During adipocyte differentiation, mRNA expressions of key adipogenic genes, including PPAR $\gamma, C / E B P \alpha, F A B P 4$, and ADIPOQ at the various time points $(24 \mathrm{~h}, 48 \mathrm{~h}$, and $8 \mathrm{~d})$ were detected. As shown in Fig. 5A-C, compared with blank control and Ad-GFP control, Ad-ZBTB16 dramatically increased expressions of PPAR $\gamma, \mathrm{C} / \mathrm{EBP} \alpha$, FABP4, and ADIPOQ through the differentiation process $(\mathrm{P}<0.01)$. Consistently, protein expression levels of PPAR $\gamma$ and FABP4 in Ad-ZBTB16 transfected cells were very significantly enhanced on day 8 of differentiation $(P<0.01)$, whereas the blank and Ad-GFP control groups did not show significant differences ( $P>0.05$; Fig. 5D). These results indicate that Ad-ZBTB16 enhanced adipogenic gene expressions and promoted adipogenesis of bovine IMF-derived preadipocytes. 


\section{Cellular Physiology Cell Physiol Biochem 2018;48:2528-2538 \begin{tabular}{ll|l} 
and Biochemistry & $\begin{array}{l}\text { DOI: 10.1159/000492697 } \\
\text { Published online: 16 August, } 2018\end{array}$ & $\begin{array}{l}\text { (c) } 2018 \text { The Author(s). Published by S. Karger AG, Basel } \\
\text { www.karger.com/cpb }\end{array}$
\end{tabular}

Ad-ZBTB16 induces brown-like adipocyte formation of bovine IMFderived preadipocytes

To investigate whether Ad-ZBTB16 induces brown-like adipocyte formation of bovine preadipocytes, relative mRNA levels of brown adipocyte selective genes (PRDM16, UCP1, Cidea, Cox8b, and PGC$1 \alpha)$ and beige adipocyte selective genes (CD137, TMEM26, and Tbx1), protein level of UCP1 gene, relative mitochondrial DNA copy number, and mitochondrial biogenesis were determined.

Results show that relative mRNA levels of both brown adipocyte selective genes and beige adipocyte selective genes in Ad-ZBTB16 treatment group were significantly higher than those in the blank control and Ad-GFP control groups (PGC-1 $\alpha$, TMEM26, and Tbx1, P $<0.01$; others, $\mathrm{P}<0.05$; Fig. $6 \mathrm{~A}$ ). Additionally, the expression level of UCP1 protein in Ad-ZBTB16 treated cells was similarly up-regulated compared with the control groups (Fig. 6B). In the Ad-ZBTB16 treatment group, relative mitochondrial DNA copy number was significantly higher than that in the blank control group and Ad-GFP control group ( $<<0.05$; Fig. 6C).

Mitochondrial biogenesis of bovine IMF-derived preadipocytes at day 8 of differentiation was detected by MitoTracker staining method (Fig. 7). As shown by notably enhanced red fluorescence in Ad-ZBTB16 treated cells, Ad-ZBTB16 treatment remarkably induced mitochondrial biogenesis in bovine adipocytes. These results indicate Ad-ZBTB16 induced brown-like adipocyte formation of bovine IMF-derived preadipocytes.

\section{Discussion}

The developmental biology of adipocytes is an important topic of research in both human medicine and farm animal production [24]. Adipogenesis is the process by which fibroblastlike preadipocyte proliferate and differentiate into lipid-filled adipocytes, accompanied by changes in the expression of adipogenesis-related transcriptional factors [4]. Identifying key genes that control adipogenesis is vital to understand adipocyte biology and regulate fat deposition. The present study provides the first evidence that ZBTB16 is a novel regulator of adipogenesis in bovine, which accelerates differentiation and induces brown-like adipocyte formation of intramuscular preadipocytes.

It has been shown that ZBTB16 gene is highly expressed in mouse adipose tissue and its expression is up-regulated during the differentiation of 3T3-L1 preadipocytes [18]. In this study, bovine preadipocytes isolated from intramuscular fat were used as the in vitro cell model. Similarly, we observed that both mRNA and protein expressions of ZBTB16 were consistently up-regulated through differentiation of preadipocytes. Moreover, by detecting cell fractions directly isolated from intramuscular fat, we found lipid-filled adipocytes possessed significantly higher expressions of ZBTB16 compared with preadipocytes. These results imply ZBTB16 may play a role in regulating fat accumulation. 


\section{Cellular Physiology Cell Physiol Biochem 2018;48:2528-2538 \\ \begin{tabular}{ll|l} 
and Biochemistry & $\begin{array}{l}\text { DOI: 10.1159/000492697 } \\
\text { Published online: 16 August, } 2018\end{array}$ & $\begin{array}{l}\text { (c) } 2018 \text { The Author(s). Published by S. Karger AG, Basel } \\
\text { www.karger.com/cpb }\end{array}$
\end{tabular}

Previous studies have demonstrated that enforced expression of ZBTB16 in several myeloid cell lines leads to inhibition of proliferation [11] and inactivation of ZBTB16 in hematopoietic stem cells results in cell cycle deregulation [17]. ZBTB16 also plays a role in suppressing the proliferation of human corneal endothelial cells [25]. To assess whether ZBTB16 regulates proliferation of preadipocytes, we used a gain-of-function assay. We found that overexpression of ZBTB16 had no effect on proliferation of bovine intramuscular preadipocytes. This result is consistent with a previous study by using a T-leukemia cell line, which showed transgenic expression of ZBTB16 alone had no detectable effect on survival or cell cycle progression [26].

As both increased number and expanded volume of adipocytes contribute to fat accumulation, we further detected ZBTB16 functions in preadipocyte differentiation. We found that ZBTB16 overexpression in preadipocytes accelerated lipid accumulation in bovine adipocytes, as evidenced by morphologic and quantitative data of the amount of triglyceride. Consistently, Ad-ZBTB16 (overexpressing ZBTB16) increased the activity of GPDH, which is an enzyme that playing a major role in lipid biosynthesis pathway within fat cells [27]. Moreover, several key adipogenic marker genes, including PPAR $\gamma, \mathrm{C} / \mathrm{EBP} \alpha$, FABP4, and ADIPOQ, were used to define the progress of adipocyte differentiation. Our data showed that Ad-ZBTB16 significantly increased expressions of the above factors through the process of differentiation. The combined results above strongly suggest that ZBTB16 positively regulates differentiation of bovine intramuscular preadipocytes. It has been reported that ZBTB16 interacts with GATA-2 and inhibits its transactivation capacity [28]. GATA-2 is a C2C2-type zinc finger protein and has been demonstrated to negatively regulate the preadipocyte-to-adipocyte transition [29]. These reports could support our conclusion about Ad-ZBTB16 functions on preadipocyte differentiation. However, Mikkelsen et al. (2010) found overexpression of ZBTB16 significantly repressed differentiation of 3T3-L1 preadipocytes whereas knockdown of this gene showed the opposite effects [18]. It was previously reported that farm animals may exhibit patterns of lipid metabolism distinctly different from rodents [24] and differentiation levels of intramuscular adipocyte differed from that of other adipose tissues [4, 30,31]. It might be possible that different species and/ or intrinsic depot-specific differences for fat cells contribute to the contradictory results for adipogenesis. For example, conjugated linoleic acid isomer caused an inhibition of differentiation in 3T3-L1 cells [32], but the contrary was found in pig primary preadipocytes [33]. Since data about the effect of ZBTB16 gene on adipogenesis is limited. More research is needed to explore ZBTB16 functions on preadipocyte differentiation.

White adipose tissue (WAT) and brown adipose tissue (BAT) are the two types of adipose tissue present in mammals. WAT-derived white adipocytes store a large amount of lipids and are mainly involved in the storage and mobilization of energy, whereas BAT-derived brown adipocytes contain abundant mitochondria and play a key role in thermogenesis [34]. Except for classical white or brown adipocytes, inducible brown-like adipocytes, also referred to as beige or brite adipocytes, emerge in WAT in response to various stimuli [35, 36]. Distinct from white or brown adipocytes, the beige cells have high mitochondrial contents but express low levels of UCP1 (uncoupling protein 1; an important marker of brown adipocyte) in the basal (unstimulated) state; upon stimulation, beige cells elevate UCP1 expression and enable thermogenesis that are similar to those of classic brown fat cells [36]. It has been reported that ZBTB16 could be induced in both the BAT and skeletal muscle during acute adaptive thermogenesis [20]. ZBTB16 overexpression in brown adipocytes led to the induction of thermogenic program, playing a role in brown adipocyte bioenergetics [20]. Thus, we speculated that, in addition to fulfilling a vital role in white preadipocyte differentiation, this novel transcription factor may modulate thermogenic action in bovine IMF-derived preadipocytes. To investigate whether ZBTB16 exerts such functions, the Ad-ZBTB16 was transfected into preadipocytes, and then stimulated to differentiate for 8 days. Our results showed that ZBTB16 overexpression remarkably increased UCP1 protein expression. In addition, relative mRNA levels of brown adipocyte selective genes (PRDM16, UCP1, Cidea, Cox8b, and PGC-1 $\alpha$ ) and beige adipocyte selective genes (CD137, TMEM26, and Tbx1) 


\section{Cellular Physiology Cell Physiol Biochem 2018;48:2528-2538 \begin{tabular}{l|l|l} 
DOI: 10.1159/000492697 & $\begin{array}{l}\text { O 2018 The Author(s). Published by S. Karger AG, Basel } \\
\text { www.karger.com/cpb }\end{array}$
\end{tabular}

were significantly increased in Ad-ZBTB16 treatment group than those in control groups. Consistently, enhanced ZBTB16 expression also accelerated mitochondrial biogenesis and increased mitochondrial number, as shown by MitoTracker staining as well as the relative mtDNA copy number. As PPAR $\gamma, \mathrm{C} / \mathrm{EBP} \alpha, \mathrm{FABP} 4$, and ADIPOQ are adipogenic markers for both WAT and BAT [37], enhanced expressions of these genes detected during preadipocyte differentiation in above data further verify the effect of ZBTB16 on promoting brown-like adipocyte formation. Taken together, these findings suggest that ZBTB16 overexpression enhances white adipogenesis and induces beige cell formation of bovine intramuscular preadipocytes. It has been well documented that PPAR $\gamma$ can promote both white and brown adipogenesis [8]. The profoundly increased PPAR $\gamma$ contents due to ZBTB16 overexpression could explain both higher brown and white adipogenesis. As GATA-2 inhibits adipocyte differentiation partially through direct binding and suppressing PPAR $\gamma$ [29], interaction of GATA-2 and ZBTB16 [28] provides a possible reason for the enhanced PPAR $\gamma$ expression due to ZBTB16 overexpression. However, regulation mechanisms of ZBTB16 require further study.

In summary, the present study used cultured intramuscular preadipocytes and adenovirus-mediated ZBTB16 gene transduction to investigate the effect and its underlying mechanisms of ZBTB16 gene on bovine intramuscular fat deposition. Our study showed that enhanced ZBTB16 promoted both white and brown-like adipogenesis of bovine intramuscular preadipocytes. Increased expressions of adipogenic transcription factors such as PPAR $\gamma, \mathrm{C} / \mathrm{EBP} \alpha, \mathrm{FABP} 4$, and ADIPOQ participated in the pro-adipogenic effects of ZBTB16. Moreover, ZBTB16 overexpression enhanced brown and beige adipocyte selective gene expressions, accelerated mitochondrial biogenesis and increased mitochondrial number, indicating that ZBTB16 also performs a functional role in the formation of white intramuscular preadipocytes to brown-like adipocytes. Taken together, our study helps to elucidate the differentiation patterns of bovine preadipocytes, improves our understanding of adipose deposition in bovine and further reveals the function of the ZBTB16 gene in the specific deposition of bovine intramuscular fat, thus providing insights into mechanisms for the use of ZBTB16 in fat management.

\section{Acknowledgements}

This research was supported by the National Natural Science Foundation of China (31501930), the Fundamental Research Funds for the Central Universities of China (KJQN201606), and the Natural Science Foundation of Jiangsu Province (BK20150656).

\section{Disclosure Statement}

No potential conflicts of interest were disclosed.

\section{References}

1 Hausman GJ, Basu U, Wei S, Hausman DB, Dodson MV: Preadipocyte and adipose tissue differentiation in meat animals: Influence of species and anatomical location. Annu Rev Anim Biosci 2014;2:323-351.

-2 Kloting N, Bluher M: Adipocyte dysfunction, inflammation and metabolic syndrome. Rev Endocr Metab Disord 2014;15:277-287.

-3 Chen J, Zhao H, Ma X, Zhang Y, Lu S, Wang Y, Zong C, Qin D, Wang Y, Yingfeng Yang Y, Wang X, Liu Y: GLP1/GLP-1R signaling in regulation of adipocyte differentiation and lipogenesis. Cell Physiol Biochem 2017;42:1165-1176. 


\section{Cellular Physiology Cell Physiol Biochem 2018;48:2528-2538 \begin{tabular}{ll|l} 
DOI: 10.1159/000492697 & $\begin{array}{l}\text { O 2018 The Author(s). Published by S. Karger AG, Basel } \\
\text { www.karger.com/cpb }\end{array}$ \\
\hline
\end{tabular} \\ Wei et al.: ZBTB16 Induces Beige Cell Formation}

-4 Hausman GJ, Dodson MV, Ajuwon K, Azain M, Barnes KM, Guan LL, Jiang Z, Poulos SP, Sainz RD, Smith S, Spurlock M, Novakofski J, Fernyhough ME, Bergen WG: Board-invited review: The biology and regulation of preadipocytes and adipocytes in meat animals. J Anim Sci 2009;87:1218-1246.

5 Liu SY, Zhang YY, Gao Y, Zhang LJ, Chen HY, Zhou Q, Chai ML, Li QY, Jiang H, Yuan B, Dai LS, Zhang JB: MiR-378 plays an important role in the differentiation of bovine preadipocytes. Cell Physiol Biochem 2015;36:1552-1562.

6 Campos CF, Duarte MS, Guimaraes SE, Verardo LL, Wei S, Du M, Jiang Z, Bergen WG, Hausman GJ, Fernyhough-Culver M, Albrecht E, Dodson MV: Review: Animal model and the current understanding of molecule dynamics of adipogenesis. Animal 2016;10:927-932.

7 Du M, Yin J, Zhu MJ: Cellular signaling pathways regulating the initial stage of adipogenesis and marbling of skeletal muscle. Meat Sci 2010;86:103-109.

$>8$ Cristancho AG, Lazar MA: Forming functional fat: A growing understanding of adipocyte differentiation. Nat Rev Mol Cell Biol 2011;12:722-734.

-9 Chen Z, Brand NJ, Chen A, Chen SJ, Tong JH, Wang ZY, Waxman S, Zelent A: Fusion between a novel Kruppellike zinc finger gene and the retinoic acid receptor-alpha locus due to a variant $\mathrm{t}(11 ; 17)$ translocation associated with acute promyelocytic leukaemia. EMBO J 1993;12:1161-1167.

10 Kolesnichenko M, Vogt PK: Understanding PLZF: Two transcriptional targets, REDD1 and smooth muscle alpha-actin, define new questions in growth control, senescence, self-renewal and tumor suppression. Cell Cycle 2011;10:771-775.

11 Dick JE, Doulatov S: The role of PLZF in human myeloid development. Ann N Y Acad Sci 2009;1176:150153.

12 Buaas FW, Kirsh AL, Sharma M, McLean DJ, Morris JL, Griswold MD, de Rooij DG, Braun RE: Plzf is required in adult male germ cells for stem cell self-renewal. Nat Genet 2004;36:647-652.

-13 Costoya JA, Hobbs RM, Barna M, Cattoretti G, Manova K, Sukhwani M, Orwig KE, Wolgemuth DJ, Pandolfi PP: Essential role of Plzf in maintenance of spermatogonial stem cells. Nat Genet 2004;36:653-659.

14 Barna M, Hawe N, Niswander L, Pandolfi PP: Plzf regulates limb and axial skeletal patterning. Nat Genet 2000;25:166-172.

15 Cheung M, Pei J, Pei Y, Jhanwar SC, Pass HI, Testa JR: The promyelocytic leukemia zinc-finger gene, PLZF, is frequently downregulated in malignant mesothelioma cells and contributes to cell survival. Oncogene 2010;29:1633-1640.

16 Felicetti F, Bottero L, Felli N, Mattia G, Labbaye C, Alvino E, Peschle C, Colombo MP, Care A: Role of PLZF in melanoma progression. Oncogene 2004;23:4567-4576.

17 Vincent-Fabert C, Platet N, Vandevelde A, Poplineau M, Koubi M, Finetti P, Tiberi G, Imbert AM, Bertucci F, Duprez E: PLZF mutation alters mouse hematopoietic stem cell function and cell cycle progression. Blood 2016;127:1881-1885.

-18 Mikkelsen TS, Xu Z, Zhang X, Wang L, Gimble JM, Lander ES, Rosen ED: Comparative epigenomic analysis of murine and human adipogenesis. Cell 2010;143:156-169.

19 Ambele MA, Dessels C, Durandt C, Pepper MS: Genome-wide analysis of gene expression during adipogenesis in human adipose-derived stromal cells reveals novel patterns of gene expression during adipocyte differentiation. Stem Cell Res 2016;16:725-734.

20 Plaisier CL, Bennett BJ, He A, Guan B, Lusis AJ, Reue K, Vergnes L: Zbtb16 has a role in brown adipocyte bioenergetics. Nutr Diabetes 2012;2:e46.

-21 Wei S, Duarte MS, Du M, Paulino PV, Jiang Z, Albrecht E, Fernyhough-Culver M, Zan L, Hausman GJ, Dodson MV: Bovine mature adipocytes readily return to a proliferative state. Tissue Cell 2012;44:385-390.

-22 Wei S, Fu X, Liang X, Zhu MJ, Jiang Z, Parish SM, Dodson MV, Zan L, Du M: Enhanced mitogenesis in stromal vascular cells derived from subcutaneous adipose tissue of Wagyu compared with those of Angus cattle. J Anim Sci 2015;93:1015-1024.

-23 Cree LM, Patel SK, Pyle A, Lynn S, Turnbull DM, Chinnery PF, Walker M: Age-related decline in mitochondrial DNA copy number in isolated human pancreatic islets. Diabetologia 2008;51:1440-1443.

-24 Dodson MV, Hausman GJ, Guan L, Du M, Rasmussen TP, Poulos SP, Mir P, Bergen WG, Fernyhough ME, McFarland DC, Rhoads RP, Soret B, Reecy JM, Velleman SG, Jiang Z: Lipid metabolism, adipocyte depot physiology and utilization of meat animals as experimental models for metabolic research. Int J Biol Sci 2010;6:691-699. 


\section{Cellular Physiology Cell Physiol Biochem 2018;48:2528-2538 \begin{tabular}{l|l|l} 
DOI: 10.1159/000492697 & $\begin{array}{l}\text { O 2018 The Author(s). Published by S. Karger AG, Basel } \\
\text { www.karger.com/cpb }\end{array}$
\end{tabular} \\ Wei et al.: ZBTB16 Induces Beige Cell Formation}

25 Joko T, Nanba D, Shiba F, Miyata K, Shiraishi A, Ohashi Y, Higashiyama S: Effects of promyelocytic leukemia zinc finger protein on the proliferation of cultured human corneal endothelial cells. Mol Vis 2007;13:649658.

-26 Wasim M, Carlet M, Mansha M, Greil R, Ploner C, Trockenbacher A, Rainer J, Kofler R: PLZF/ZBTB16, a glucocorticoid response gene in acute lymphoblastic leukemia, interferes with glucocorticoid-induced apoptosis. J Steroid Biochem Mol Biol 2010;120:218-227.

27 Wise LS, Green H: Participation of one isozyme of cytosolic glycerophosphate dehydrogenase in the adipose conversion of 3T3 cells. J Biol Chem 1979;254:273-275.

-28 Tsuzuki S, Enver T: Interactions of GATA-2 with the promyelocytic leukemia zinc finger (PLZF) protein, its homologue FAZF, and the $\mathrm{t}(11 ; 17)$-generated PLZF-retinoic acid receptor alpha oncoprotein. Blood 2002;99:3404-3410.

-29 Tong Q Dalgin G, Xu H, Ting CN, Leiden JM, Hotamisligil GS: Function of GATA transcription factors in preadipocyte-adipocyte transition. Science 2000;290:134-138.

30 Chen J, Dodson MV, Jiang Z: Cellular and molecular comparison of redifferentiation of intramuscular- and visceral-adipocyte derived progeny cells. Int J Biol Sci 2010;6:80-88.

31 Gardan D, Gondret F, Louveau I: Lipid metabolism and secretory function of porcine intramuscular adipocytes compared with subcutaneous and perirenal adipocytes. Am J Physiol Endocrinol Metab 2006;291:E372-380.

32 Brodie AE, Manning VA, Ferguson KR, Jewell DE, Hu CY: Conjugated linoleic acid inhibits differentiation of pre- and post- confluent 3T3-L1 preadipocytes but inhibits cell proliferation only in preconfluent cells. J Nutr 1999;129:602-606.

33 Ding ST, Schinckel AP, Weber TE, Mersmann HJ: Expression of porcine transcription factors and genes related to fatty acid metabolism in different tissues and genetic populations. J Anim Sci 2000;78:21272134 .

34 Wei S, Du M, Jiang Z, Hausman GJ, Zhang L, Dodson MV: Long noncoding RNAs in regulating adipogenesis: New RNAs shed lights on obesity. Cell Mol Life Sci 2016;73:2079-2087.

35 Petrovic N, Walden TB, Shabalina IG, Timmons JA, Cannon B, Nedergaard J: Chronic peroxisome proliferator-activated receptor gamma (PPARgamma) activation of epididymally derived white adipocyte cultures reveals a population of thermogenically competent, UCP1-containing adipocytes molecularly distinct from classic brown adipocytes. J Biol Chem 2010;285:7153-7164.

-36 Wu J, Bostrom P, Sparks LM, Ye L, Choi JH, Giang AH, Khandekar M, Virtanen KA, Nuutila P, Schaart G, Huang K, Tu H, van Marken Lichtenbelt WD, Hoeks J, Enerback S, Schrauwen P, Spiegelman BM: Beige adipocytes are a distinct type of thermogenic fat cell in mouse and human. Cell 2012;150:366-376.

37 Molchadsky A, Ezra O, Amendola PG, Krantz D, Kogan-Sakin I, Buganim Y, Rivlin N, Goldfinger N, Folgiero V, Falcioni R, Sarig R, Rotter V: p53 is required for brown adipogenic differentiation and has a protective role against diet-induced obesity. Cell Death Differ 2013;20:774-783. 